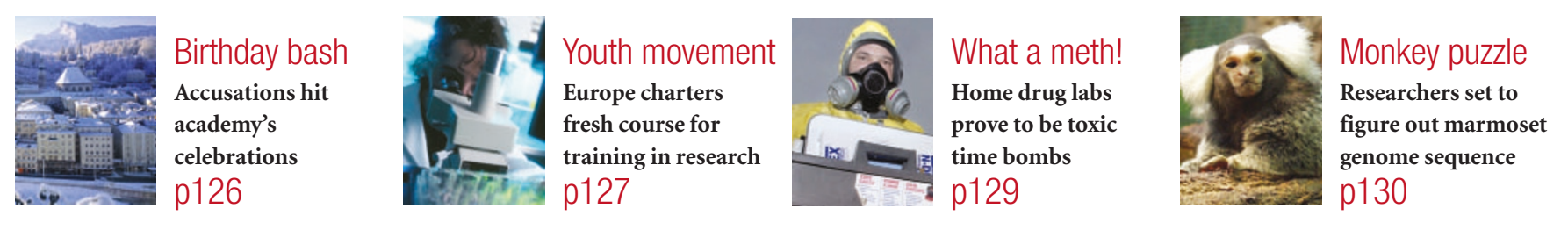

\title{
NASA's funding shortfall means journey's end for Voyager probes
}

Tony Reichhardt, Washington NASA has told scientists working on some of the agency's longest-running space missions - including the twin Voyagers now speeding towards the edge of the Solar System - that they may have to shut down operations in October to save money.

The decision — which NASA officials say is not yet final - has angered scientists, who call it penny-wise and pound-foolish, and say that it is being made without the usual formal review by the science community.

The agency's Earth-Sun System division originally planned to spend $\$ 74$ million next year to operate spacecraft that study the Sun's environment and to pay for data analysis. But the budget has since been cut to $\$ 53$ million, as NASA struggles to fund all of its planned projects. Faced with the shortfall, division officials last month informed the managers of seven missions that are past their prime lifetime - Voyager, Ulysses, Polar, Wind, Geotail, FAST (Fast Auroral SnapshoT) and TRACE (Transition Region and Coronal Explorer) - that there is no money to keep them operating after the current fiscal year ends in October.

Launched in 1977, Voyagers 1 and 2 are now more than 14 billion and 11 billion kilometres from Earth, respectively. Having visited all the outer planets except Pluto, they are on their final quest - to locate the shifting boundary between the Sun's domain and the realm where interstellar space begins. Ground antennas are in daily contact with the spacecraft, which are expected to last until about 2020 before giving out. The Voyagers cost NASA about $\$ 4.2$ million a year for operations and data analysis.

To afford new projects, NASA occasionally has to turn off spacecraft that are still

advice on how to allocate resources would probably have been different. Voyager project scientist Edward Stone of the California Institute of Technology says that instead of holding another review (the next one is scheduled for spring 2006), NASA "just worked up the old list until they matched the lower budget. But that really defeats the purpose of the senior review, which at the time was predicated on a certain level of funding."

Lennard Fisk, a University of Michigan space scientist who chairs the National Academy of Sciences Space Studies Board and is a former head of NASA space science, calls the threatened cuts "an extremely foolish thing to do". Voyager, he says, is entering one of the most

working but that have exceeded their life expectancy. Every two or three years, a'senior review' of outside scientists ranks the science value of currently operating missions to help the agency plan which ones should be extended and which shut down. The last such review for Earth-Sun System missions was in August 2003, and the projects now facing termination ranked lowest in that exercise.

\section{Out of time}

But the panel never suggested that the lowranking missions should be shut down this year. For example, Ulysses, launched in 1990 to explore the Sun's polar regions for the first time, was recommended to continue until 2008, and Wind until 2007. The Voyagers were recommended for funding until at least 2006, after which they would have to be reviewed again.

Stephen Keil of the National Solar Observatory, who chaired the 2003 review, says his panel assumed a budget of $\$ 74$ million for 2006, and although their rankings might have been the same given a lower budget, their interesting scientific phases of its long life as its particle detectors approach the edge of the Solar System. "There is no replacement for Voyager," he adds - no other working spacecraft have travelled so far from Earth, and no new ones are being built to follow them. Similarly, says Fisk, it "doesn't make sense" to turn off Ulysses just as the Sun comes to the end of a 22-year magnetic cycle.

Scientists from the threatened missions are already lobbying their congressional delegations to try to get the money restored, and Fisk thinks NASA could easily solve the budget problem by shifting funds within its \$2-billion budget for the Earth-Sun System.

That may, in fact, happen. "There's been no final decision at NASA headquarters to terminate any of these missions, despite what budget figures may imply," says NASA spokeswoman Gretchen Cook-Anderson. But for now, project scientists say they have no choice but to take the threat seriously. Having been told by NASA that there is no money available after October, Stone says, "we are currently developing a plan for shutdown". 